\title{
China lung transplantation developing: past, present and future
}

\author{
Bo Wu ${ }^{1 \#}$, Chunxiao Hu ${ }^{1 \#}$, Wenhui Chen ${ }^{2}$, Jianxing $\mathrm{He}^{3}$, Gening Jiang ${ }^{4}$, Ji Zhang ${ }^{1}$, Dong Liu ${ }^{1}$, \\ Xiaoshan $\mathrm{Li}^{1}$, Dong Wei ${ }^{1}$, Guohui Jiao ${ }^{1}$, Chen Wang ${ }^{2}$, Jingyu Chen ${ }^{1,2}$ \\ ${ }^{1}$ Wuxi Lung Transplant Center, Wuxi People's Hospital Affiliated to Nanjing Medical University, Wuxi 214000, China; ${ }^{2}$ Center for Lung \\ Transplantation, China-Japan Friendship Hospital, Beijing 100000, China; ${ }^{3}$ Department of Thoracic Surgery/Oncology State Key Laboratory and \\ National Clinical Research Center for Respiratory Disease, the First Affiliated Hospital of Guangzhou Medical University, Guangzhou 510000, \\ China; ${ }^{4}$ Department of Thoracic Surgery, Shanghai Pulmonary Hospital, Tongji University School of Medicine, Shanghai 200000, China \\ Contributions: (I) Conception and design: B Wu, C Hu, C Wang, J Chen; (II) Administrative support: C Hu, C Wang, J Chen; (III) Provision of \\ study materials or patients: C Hu, W Chen, J He, G Jiang; (IV) Collection and assembly of data: J Zhang, D Liu, X Li, D Wei; (V) Data analysis and \\ interpretation: B Wu, C Hu, G Jiao; (VI) Manuscript writing: All authors; (VII) Final approval of manuscript: All authors. \\ \#These authors contributed equally to this work. \\ Correspondence to: Jingyu Chen. Wuxi Lung Transplant Center, Wuxi People’s Hospital Affiliated to Nanjing Medical University, Wuxi 214000, \\ China. Email: chenjy@wuxiph.com; Chen Wang. Center for Lung Transplantation, China-Japan Friendship Hospital, Beijing 100000, China. \\ Email: cyh-birm@263.net.
}

\begin{abstract}
Lung transplantation in China has been developing for almost 40 years (1979-2019). The pioneers of this procedure experienced struggles and obstacles upon accomplishment of the initial 20 cases of lung transplantation. Like the expanding process of transplant programs elsewhere in western countries and other regions in Asia, transplant teams in China have found their own way to step forward, with the establishment of the two largest centers in Beijing and Wuxi. Since 2015, which was a novel start and milestone for transplant affairs in China, the pace of transplant volume and comparable quality of care for lung transplant recipients have increased noticeably. We reviewed the advancement of lung transplantation programs and registry setup in China and indicated that more socioeconomic factors and human care aspects needed to be considered to benefit Chinese recipients, which may further inspire the modification of criteria of listing and organ utilization based on East Asian cultural and traditional origins.
\end{abstract}

Keywords: Lung transplantation; China; registry; organ donation

Submitted Sep 18, 2019. Accepted for publication Sep 25, 2019.

doi: 10.21037/atm.2019.10.26

View this article at: http://dx.doi.org/10.21037/atm.2019.10.26

The evolution of lung transplant medicine has been accomplished with innovative translational research on endstage lung diseases and contribution from forerunners all over the world. Lung transplantation in China has struggled like other places in the world, and found its way through the resolution and determination of its practitioners. The year 2015 marked a milestone for Chinese organ transplantation, and since then, all the participants, including surgeons, physicians, scientists, and coordinators, have taken the opportunity to refine and amplify the accomplishments of the predecessors in the field from China and throughout the world.

\section{History of China lung transplantation (from 1979-2002)}

Dr. Norman Bethune was one of the great heroes who dedicated his life to the Chinese people, and had hopes that the youth of China would become prominent doctors in the coming decades. In fact, one of Dr. Bethune's assistants, Dr. Xin Yuling, grew up to be a prominent surgeon and performed the first lung transplantation in China. During his training days in Moscow, Dr. Xin was deeply impressed by what he had witnessed in the Laboratory for Organ Transplantation, at the Sklifosovsky Emergency Institute which was directed by Dr. Vladimir P. Demikhov. In 
1946, Dr. Demikhov was the first in the Soviet Union to accomplish a heart-lung transplant in dogs with hours-tomonths survival (1), but the barriers of the Cold War veiled this accomplishment from global acknowledgment until the 1960s (2).

Inspired by this incredible surgery, and after years of research and clinical preparation, Dr. Xin launched the first case of lung transplantation in the Beijing Institute of Tuberculosis. A 31-year-old female with a severely damaged left lung and adhesion due to tuberculosis was determined to be the first candidate for single lung transplantation. On Jan $13^{\text {th }}, 1979$, the challenging surgery took surgeons more than 5 hours meticulous dissection with blood loss of $3.8 \mathrm{~L}$. The ischemic time of the graft was 4 hours and 15 minutes. On post-operation day 5 , the transplanted lung was complete white-out and had to be resected on day 7 (3).

Following this, on November $17^{\text {th }}, 1979$, a 22 -year-old female with a similar situation received lobar transplantation from a mismatched donor lung in a much shorter period of ischemic time: 1 hour and 47 minutes. The patient still suffered unmanageable acute rejection; thus, the lobe was dissected and the patient died of pulmonary embolism on day 32 (4). Although cyclosporine had been used in China, concerns had been raised relating to lung transplantation for severe pulmonary tuberculosis (5).

Halted for over 10 years, on February $23^{\text {rd }}$, 1995, a case of left lung transplantation was performed for a patient with pulmonary fibrosis secondary to sarcoidosis, in Beijing Anzhen Hospital by Professor Chen Yuping. This was the first case to survive up to 5 years (6). The next year, in 1996, three consecutive male cases were performed by Professor Zhao Fengrui in the Beijing China-Japan Friendship Hospital. Indications were emphysema and right upper lobe squamous cell cancer along with pulmonary tuberculosis and pulmonary fibrosis. All the patients received single lung transplants. Unfortunately, all patients died: one from severe infection on post operation day 48, the other two from acute rejection on post operation days 9 and 43 . When these cases with experiences were systematically summarized, surgeons began to have a much better idea of the donorrecipient selection criteria, transplant techniques, and peritransplantation management, especially for monitoring and differentiating infection events and rejection occurrence. They became aware of human leukocyte antigen (HLA) matching in transplantation and the role of transbronchial biopsy, while rejection and infection have been recognized as the most significant contributors to death $(7,8)$.

Two years later, on January $20^{\text {th }}$, 1998 , bilateral sequential lung transplantation was performed for a pulmonary artery hypertension (PAH) patient in Beijing Anzhen Hospital. The patient survived for 4 years and 3 months, which was recognized as the first successful bilateral transplantation case in China (9). By the end of 1998, 20 cases had been completed in centers located in Beijing, Guangzhou, Shanghai and other cities with a relatively large proportion of patients. Although the procedure was maturing in terms of the proliferation of successful techniques, difficulties in managing infection and rejection remained to be major obstacles in reaching expected survival, and another 5 years of stagnation followed (Table 1).

Training and education for the procedure were ongoing in this period. Since the 1990s, thoracic surgeons have been going to the Medical Center of Washington University in St. Louis for lung transplant training. More surgeons and physicians have been sent to famous lung transplant centers to learn techniques and perioperative management strategies. Astonishing parallels can often be found in history when another fellow doctor witnessed the incredible surgery of lung transplantation in Beijing and Toronto. In September, 2002, after being trained on up-to-date lung transplantation techniques in Canada, the home country of Dr. Bethune, Dr. Jingyu Chen successfully performed single lung transplantation for a patient with emphysema (10). Coincidentally, 15 years later, Dr. Chen revitalized the lung transplantation program in the China-Japan Hospital, which was witnessed by Dr. Xin and all those who cherished the memories of struggle during those early days (Figure 1). Dr. Chen, with his Wuxi lung transplantation group, has been a pioneer in the multidisciplinary care of lung recipients, which includes efforts from surgeons, pulmonologists, intensive care staffs and rehabilitation doctors. Initially, it was an imitation of Toronto's model for transplantation team operation; as time has passed, however, there has been an emerging success informed by experiences of a Chinese origin. With more local lung transplant programs being established in the $21^{\text {st }}$ century, staffs from centers of Shanghai, Guangzhou, Wuhan, Xi'an and Jilin have been trained abroad and have brought back updated knowledge, further narrowing the gaps between China and the world.

\section{Asian involvement in lung transplantation on the global-scale}

\section{The dark and glorious days of early lung transplantation}

Looking beyond Word War II, the "golden era" of solid 
Table 1 Case summary of early lung transplantation in China (1979-2002)

\begin{tabular}{|c|c|c|c|c|c|c|c|c|}
\hline Date & Hospital & $\begin{array}{l}\text { Gender/ } \\
\text { age (years) }\end{array}$ & Indication & Type & $\begin{array}{l}\text { Operation } \\
\text { time (min) }\end{array}$ & $\begin{array}{l}\text { Ischemic } \\
\text { time (min) }\end{array}$ & Complications & Follow-up \\
\hline Jan $13^{\text {rd }}, 1979$ & $\begin{array}{l}\text { Beijing Institute of } \\
\text { Tuberculosis }\end{array}$ & Female/31 & Tuberculosis & $\begin{array}{l}\text { Single lung } \\
\text { transplantation }\end{array}$ & 345 & 255 & $\begin{array}{l}\text { Acute } \\
\text { rejection }\end{array}$ & $\begin{array}{l}\text { Resection of } \\
\text { graft on day } 7\end{array}$ \\
\hline Nov $17^{\text {th }}, 1979$ & $\begin{array}{l}\text { Beijing Institute of } \\
\text { Tuberculosis }\end{array}$ & Female/22 & Tuberculosis & $\begin{array}{l}\text { Lobar } \\
\text { transplantation }\end{array}$ & - & 107 & $\begin{array}{l}\text { Acute } \\
\text { rejection }\end{array}$ & $\begin{array}{l}\text { Died of PE on } \\
\text { day } 32\end{array}$ \\
\hline \multirow[t]{2}{*}{$1995-1997$} & $\begin{array}{l}\text { Beijing China-Japan } \\
\text { Friendship Hospital }\end{array}$ & Male/48 & $\begin{array}{l}\text { Pulmonary } \\
\text { fibrosis }\end{array}$ & $\begin{array}{l}\text { Single lung } \\
\text { transplantation }\end{array}$ & - & - & $\begin{array}{l}\text { Acute } \\
\text { rejection }\end{array}$ & $\begin{array}{l}\text { Died on infection } \\
\text { on day } 9\end{array}$ \\
\hline & & Male/56 & COPD, SCC & & - & - & $\begin{array}{l}\text { Acute } \\
\text { rejection }\end{array}$ & $\begin{array}{l}\text { Died on infection } \\
\text { on day } 48\end{array}$ \\
\hline Jan 20 $0^{\text {th }}, 1998$ & $\begin{array}{l}\text { Beijing Anzhen } \\
\text { Hospital }\end{array}$ & Male/30 & PAH & $\begin{array}{l}\text { Bilateral lung } \\
\text { transplantation }\end{array}$ & 540 & $\begin{array}{c}\text { Right } \\
245 \text {, left } \\
415\end{array}$ & $\begin{array}{l}\text { IRI, } \\
\text { anastomosis } \\
\text { stenosis, } \\
\text { tuberculosis, } \\
\text { CMV infection }\end{array}$ & $\begin{array}{l}\text { Survived in } \\
\text { follow-up to } \\
2 \text { years }\end{array}$ \\
\hline Sep $28^{\text {th }}, 2002$ & $\begin{array}{l}\text { Wuxi Lung } \\
\text { Transplant center }\end{array}$ & Male/56 & $\begin{array}{l}\text { COPD, } \\
\text { emphysema }\end{array}$ & $\begin{array}{l}\text { Single lung } \\
\text { transplantation }\end{array}$ & 320 & 260 & $\begin{array}{l}\text { Acute } \\
\text { rejection }\end{array}$ & $\begin{array}{l}\text { Discharged at } \\
\text { day } 47\end{array}$ \\
\hline
\end{tabular}

PE, pulmonary embolism; SCC, squamous cell carcinoma; PAH, pulmonary artery hypertension.

organ transplantation began along with the advancement of surgical techniques, anesthesiology, antibiotics, and immunosuppressants through years of experimental research. Most of the history of lung transplantation has been thoroughly reviewed in the literature and is summarized Figure 2. In many textbooks and papers, the first successful lung transplantation was undoubtedly attributed to what have occurred in Toronto in 1983 (11). There are many more great individuals who should be remembered for their contributions to the progress of lung transplantation science. Dr. James Hardy was among them, and his work in the early years, although contentious, could not be ignored.

Based on an abundance of animal experiences, Dr. Hardy and his colleagues at the University of Mississippi Medical Center first demonstrated that azathioprine had a better effect at warding off rejection (12). As a result of tirelessly introducing what he had done at surgical conferences, Dr. Hardy earned his chance to perform the first lung transplantation on a human being with restricted selection criteria in 1963 (13). He performed a more aggressive procedure of transplanting a chimpanzee heart to a deaf and mute patient who had limited ability of consent. The patient survived for 90 minutes after surgery, thus raised a storm of concerns ethically. With fear derived from a cruel history of Nazi practice on living experiments, people were threatened by the medical ethics misconduct.

Informed consent and institutional review boards were two key parts of aggressive medical interventional research approval. Whether to use prisoners in experimental medicine had long been a dispute of ethical consideration. Some even criticized Dr. Hardy's chasing of the first lung transplant. The high rate of death and morbidities did not deter the up-coming candidates, Dr. Hardy was suffering a "desperate in need of help". No other clinical procedures like transplantation, risks were further added on a dying person. Doctors like Hardy, continued to take risk with such patients under great pressure; their ambitious work combined with the candidate's willingness of being the "first-to-try", became the impetus of this great field.

Only a few cases were performed in the following years, but by only prolonging survival for a few days, many 

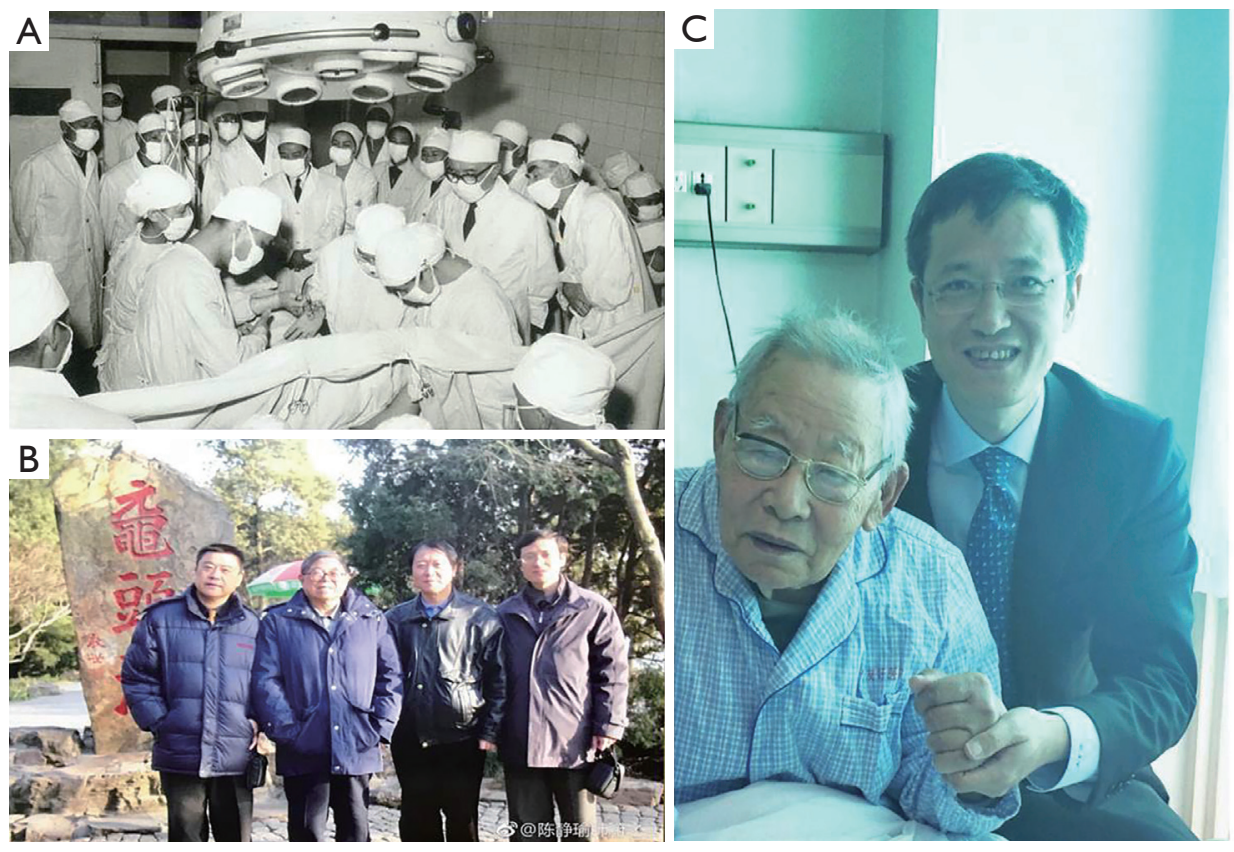

Figure 1 Memory of China lung transplantation stepping forward in 40 years. (A) In 1979, Dr. Xin performed the first lung transplantation case (Courtesy of China-Japan Hospital); (B) in 2003, Dr. Yuping Chen, Dr. Fengrui Zhao, Dr. Jingyu Chen and Dr. Guoliang Zhang, the key pioneers in Chinese lung transplantation, gathering in a meeting; (C) in 2017, Dr. Chen took charge of the Lung Transplant Center at the Beijing-China Friendship Hospital; photo taken with the former chief of the hospital, Dr. Yuling Xin.

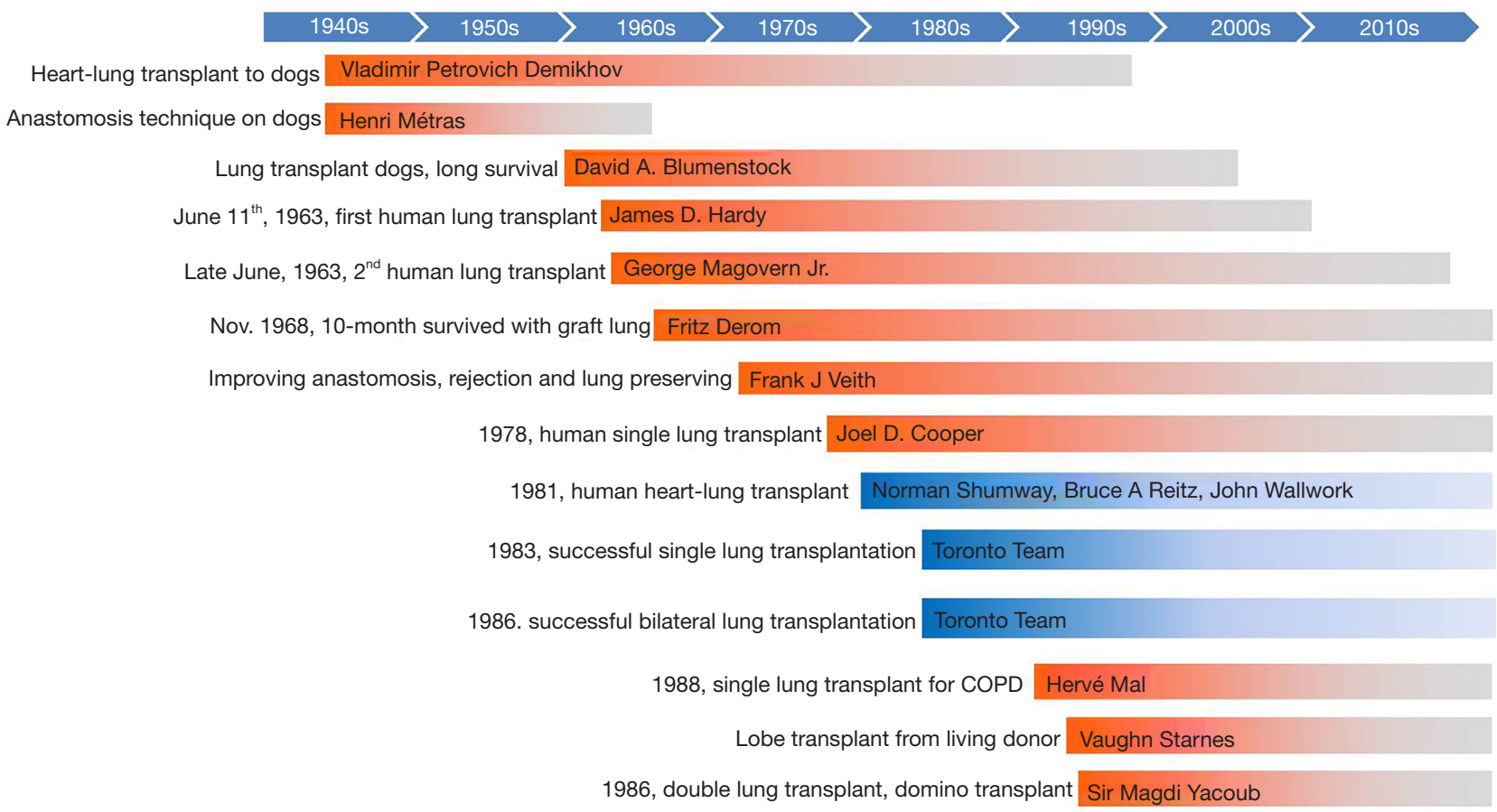

Figure 2 Attempts before fully established lung transplantation techniques. History of lung transplantation with those pioneers who began their work before the 1990s. 
people were skeptical as to whether organ transplanters' experimental techniques on humans were worthy of the moral costs. Facing years of questions and challenges, people called it "transplantation's darkest time" (14). The "embers of hope" were kept by Dr. Frank Veith at the Montefiore Hospital in New York; he persisted in modifying bronchial anastomosis techniques (15); meanwhile, Dr. Griffith Pearson in Toronto led a team following the work of Dr. Joel Cooper, a maverick from Harvard, who attended the development of extracorporeal membrane oxygenation (ECMO), and attempted a single lung transplant in 1978 (16). The great discovery of cyclosporine was another fortunate development for lung transplantation. By the late 1970s, by virtue of being the first permitted to use cyclosporine, Veith's program at Montefiore and the Toronto team gained impressive initial results. Thereafter, the Toronto team had a 6.5 -year survival recipient $(11,17)$, while Dr. Mal from France had a successful case of single lung transplantation for chronic obstructive pulmonary disease (COPD) (18).

From 1963 to 1983 , there were approximately 20 more attempts to perform lung transplants, but mere months of survival were achieved. China has experienced the same frustration, lagging behind by 10 years from the initial phase. By virtue of the world's developing knowledge, it was uplifting to see two Chinese recipients achieving long-term survival in the first 20 years of China lung transplantation development. Given this difficult history, we should remember and recognize those who persisted in the dark times when we marveled at and applauded the modern success of lung transplantation. Now, technique advancement and improvements in new drugs and facilities bring a golden era for lung transplantation.

\section{Investigation on practice of lung transplantation in Asia}

The Asian Society of Transplantation (AST) was fully established in 1989 with the initiation of Asian transplant registry. Data was compiled from all the countries who were registered (19). The largest set of lung transplant data was from Thailand between the year of 1993 and 1995 (20). The annual number of lung transplants in Asia increased from 3 (1994) to 14 (1997). By 1999, Japan started living donor lung transplantation with 14 cases reported in 2003 (21) and until today, most of the reports on living-donor lobar lung transplantation have been from Japan (22). While there was a fluctuation of annual heart transplants, there was a relatively stable increasing trend of lung transplantation (23).
Between 1998 and 2002, the collected number of lung transplants had reached 106, mostly from Japan, Thailand, Taiwan region and Hong Kong region (24).

China has established the China Lung Transplantation Registry (CLuTR) and opened the statistical data to academics. The first case report was conducted in 2011 (25). From January $1^{\text {st }}, 2015$ to December $31^{\text {st }}, 2018$, after the law was fully established and guaranteed the legislation and ethical compliance in the procedures, 1,053 recipients' data were recorded. In line with what was already known from Chinese registry, idiopathic interstitial pneumonitis (IIP) and COPD were among the largest categories. One year and 3-year survival rates in CLuTR were $70.11 \%$ and $61.16 \%$ respectively, with discrepancy of indications and significantly higher percentage of senile candidates (Figure 3).

The first cadaveric lung transplantation in the Taiwan region was performed in 1991. The Taiwan region has established an urgency-based national allocation policy and only authorized centers with over 5 cases/ year. We can see (Figure 3C) in the representative data from the National Taiwan University Hospital (Taipei, Taiwan region) that between 1995 and 2016, 92 lung transplantations were performed and categorized by chronic obstructive pulmonary disease (COPD), pulmonary arterial hypertension, cystic fibrosis, and idiopathic pulmonary fibrosis. The 1 -year survival from 2006 to 2016 was $85 \%$ (27). As the largest cohort of lung transplantation in Taiwan region developed for over 20 years, current team has established procedures like delayed chest closure, graft trimming, early tracheostomy, and put them into practice. However, with continuous technique development, some controversial issues would be better solved with cumulative and expanding institutional experiences.

The first single lung transplantation performed in the Hong Kong region was by Dr. Clement S. W. Chiu for a lymphangioleiomyomatosis (LAM) patient in 1995. The average number of lung transplants has increased to 12 cases per year. Sixty cases have been transplanted until August, 2017 (Figure 3B). Pulmonary circulation disease candidates composed the largest part of the Hong Kong waiting list, while obstructive lung disease patients underwent the highest percentage of transplants. Like what we have seen in the Mainland China data, LAM had a relatively higher percentage in recipients, which was different from western countries. Survival data has also been promising with 1-, 5-, and 10-year survival being 90.9\%, 71.5\%, and $54.5 \%$, respectively. Among indication categories, LAM, 

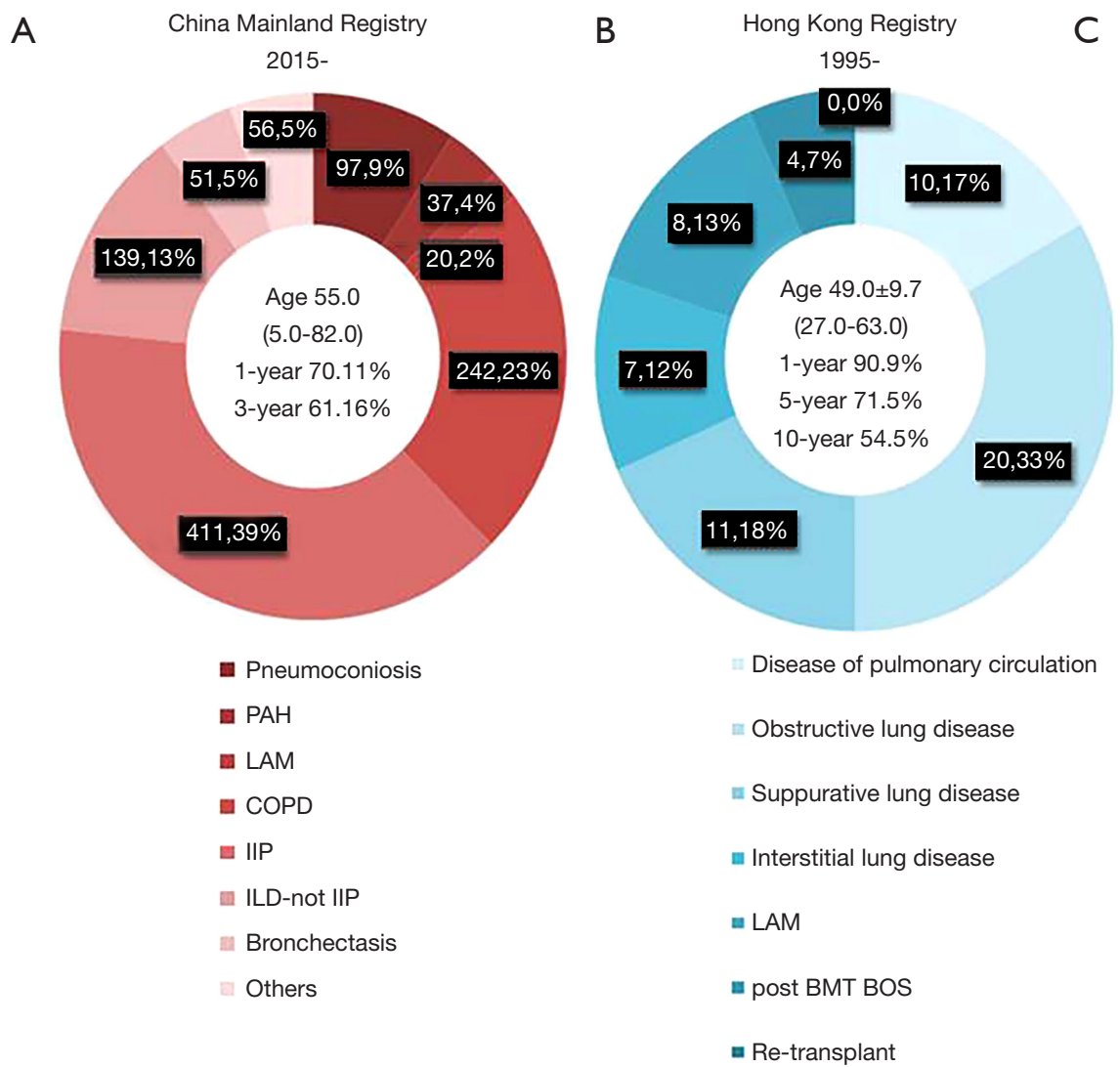
A

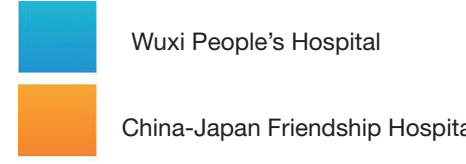

ital
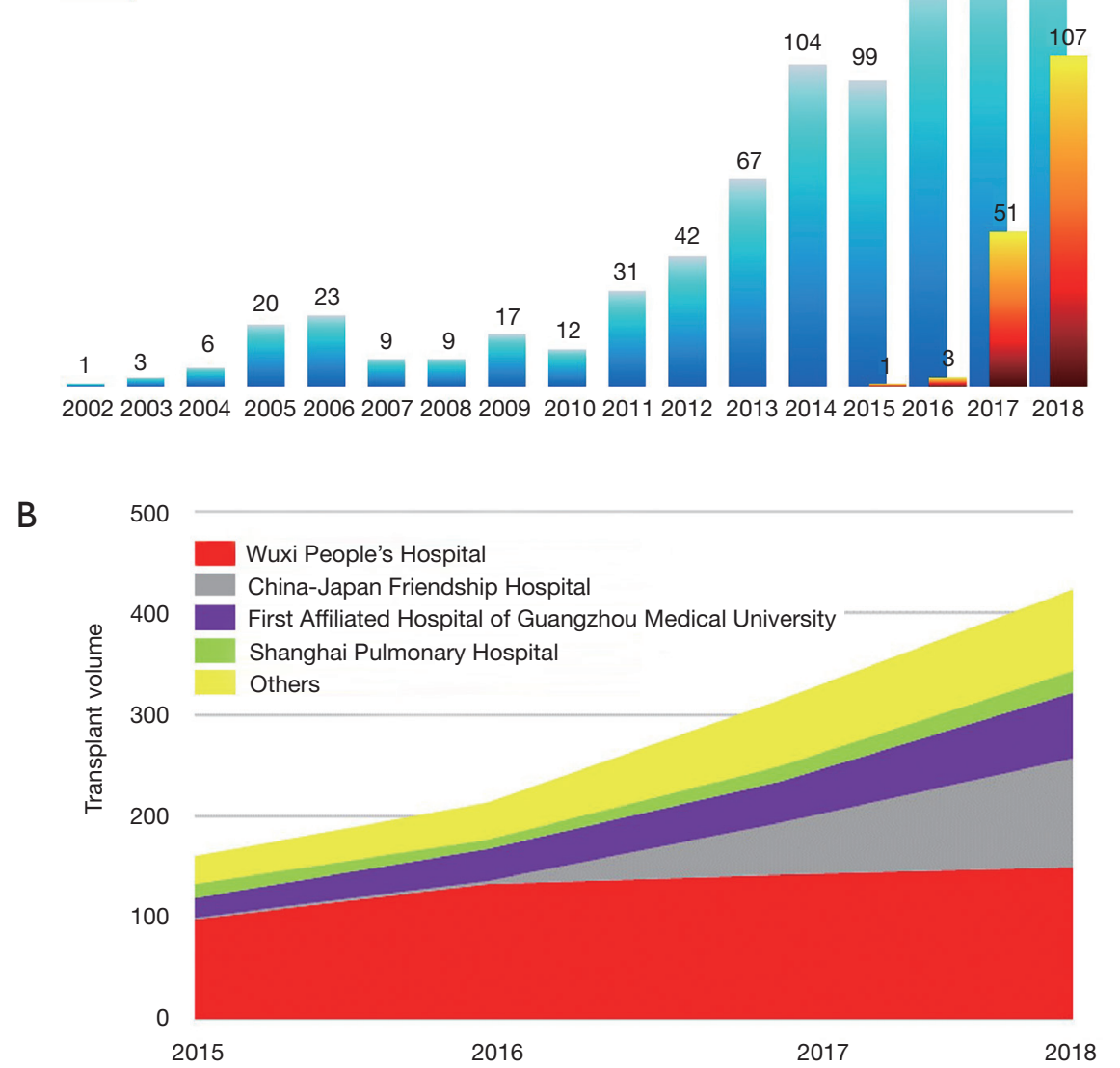

Figure 4 Expanding volume of lung transplantation centers in China. (A) Yearly lung transplantation volume in Wuxi center (blue bar) and Beijing center (orange bar), with the figure trend showing a sharp increase in the Beijing center in 2 years compared to 15 years at the Wuxi center; (B) with increment of lung transplantation nationwide since 2015 , more cases have been performed in emerging centers.

quantity and quality (Figure 4B). "Green channel of human organ transportation" has been established in 2016, facilitating the long-distance organ transportation and allocation.

Beyond the common practice of lung transplantation, Wuxi team explored further on the feasibility of the technique application, including transplants for bronchiectasis in an asymmetric thorax (32), simultaneous Nuss surgery and transplantation, transplants for cancer patients (33-35), lung size-matching and complications discussion with international peers (36-38), all which have attracted much more attention from outside China. With the case volume expanding, technical obstacles and clinical difficulties have also become the research focus for the present and future. Lung transplantation in idiopathic pulmonary fibrosis (39-41) and bronchiolitis obliterans syndrome after allogenic hematopoietic stem cell transplantation (42), especially in pediatric candidates, and critical care of end-stage patients listed $(43,44)$ have been on-going accumulation of data and experiences.

The Wuxi center, with its prominent presentation, was authorized to take over the supervisor role of China lung transplant data in 2010, as the data quality control and management center. Wuxi has also been the leading center for lung transplant training, not only sharing experiences with qualified centers, but also taking the on-board staff training for emerging centers in the second- or third-tier cities in China. For the past ten years, we have trained more 


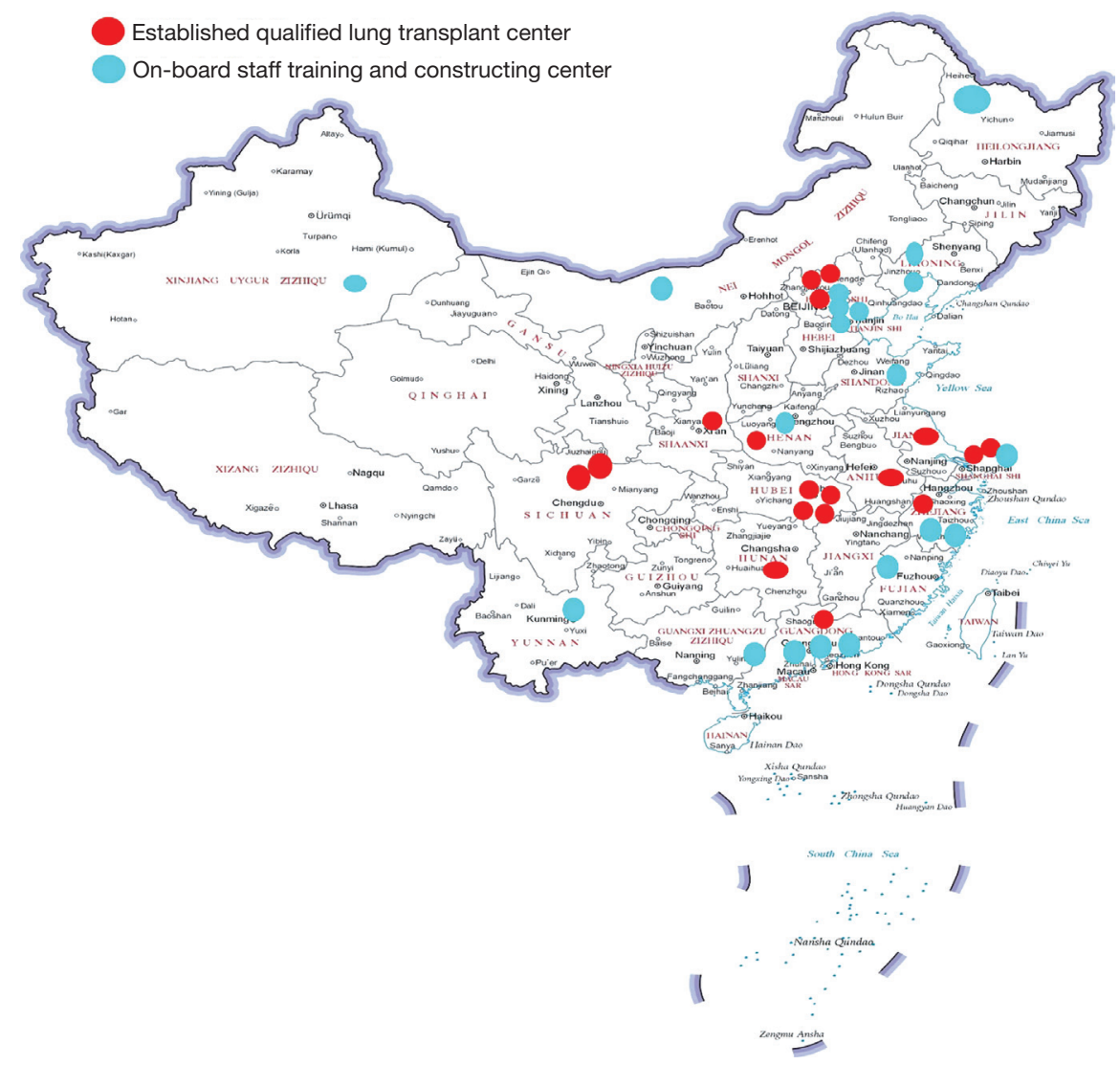

Figure 5 Distribution model of qualified lung transplantation centers registered in China (red) and the emerging teams trained by the Wuxi or Beijing teams (blue). [Map cited from http://bzdt.ch.mnr.gov.cn/ and approved number GS (2019) 1671].

than 500 medical staffs from more than 20 provinces and 30 hospitals, including surgeons, pulmonary physicians, anesthetists and nurses. For the centers in the labeled location on the maps, our teams have performed all the start-over lung transplants with local team and further trained staffs (Figure 5). More academic activities have been initiated with centers outside Mainland China, including with Macau Kiang Wu Hospital, Taiwan Chang Gung Memorial Hospital, Saudi Arabia King Salman Hospital and centers in the Philippines.

\section{How has the Beijing center program developed?}

Years after the initial cases, lung transplantation still maintains its position in the Beijing China-Japan Friendship hospital (Beijing center). After the year 2000, several cases of lung transplantation, including 1 case of cystic fibrosis, were successfully performed (45). However, there was still a high mortality of patients with poor heart-lung function pre-transplantation and severe infection with immunosuppressants (46). Transplantation research has also focused on animal models, such as canine and modified rat lung transplantation model, as well as perfusate formulation modification, in order to prolong the preserving time of graft lungs in animal experiments.

During the period between March $3^{\text {rd }}, 2017$, and June $29^{\text {th }}, 2018,100$ cases of lung transplantation were performed in the Beijing Center. The average age of the cohort was $58.2 \pm 11.2$ years old. More than $70 \%$ of the patients were diagnosed as pulmonary fibrosis. The peri-operative period survival ( $<30$ days) rate was $78 \%$. Since 2017, after Dr. Chen from the Wuxi Center became the deputy director of the Beijing center, the Beijing center has seen an upsurge, with collaboration being strongly reinforced with the Department of Respiratory and Critical Care team in the hospital. With a fast-maturing surgery and management team, this center has been the lung transplantation center with the highest increment rate of transplant volume per 
year. Many more complex cases, such as severe pulmonary artery hypertension, donated lung from a donor with 5 months of tracheotomy, recipients with multi-drugs resistant infection, rare fungal infection (47), 100\% positive PRA and pulmonary veno-occlusive disease recipients, were handled uneventfully.

As can be seen from the national registry and data from centers, occupation-related diseases were one of the main categories in Chinese lung transplantation patients. This patient group had unique physical and financial difficulties. Foundations to help these groups of patients, such as funds for pneumoconiosis, were established in the Beijing center in order to provide public welfare assistance and conduct practical research on these kinds of diseases.

Ever since Dr. Xin became the first president of the China-Japan Hospital with the first lung transplantation case in China, lung transplantation research and clinical practice have never ceased. However, in 2017, with the importation of the Wuxi model of establishing a lung transplantation team, there has been a sharp increment of transplant volume in Beijing center within 2 years comparable to the 15-year of Wuxi center's growth. Successes achieved in Beijing may contribute enormously to nationwide lung transplantation growth and encourage more centers to have devoted transplant teams.

The Wuxi and Beijing centers have been recognized as the leaders in Chinese lung transplantation and the chief contributors to bolster the growth of new centers. As in the early years of the Stanford and Toronto transplant programs, this has been accomplished with tenacious surgeons coordinating dedicated teams made up of surgeons, immunologists, anesthesiologists, hematologists, pulmonary physicians, physical therapists, intensive care and ward nurses, psychiatrists, social workers, and lab technicians. This team not only supports their own centers, but also works with referring physicians and nonmedical people to procure organs. To construct and expand a lung transplantation program may need some ambition, but what defines the success of the program is the persistent teamwork and strict ethics, not to mention good timing and the patient's courage to take risks.

\section{Essential supports of lung transplantation program development}

Legal system construction to guarantee organ procurement and utilization

Lung transplantation is not only determined by surgical techniques, but is also an issue related to social progress and public acknowledgement. In 2003, the initial official criterion for brain death was established by the Chinese Ministry of Health $(\mathrm{CMH})$, providing the knowledge and legal foundation for the organ donation program to expand. Later, in 2007, Regulations on Human Organ Transplantation became the first organ transplantation law in China to be promulgated by the State Council. The law provided the legal basis to support the development of qualified transplant centers and limit the illegal use of organs. More than a hundred centers have been authorized to perform organ transplantation, while there were only 20 centers which were qualified to do lung transplantation when the authentication process first launched (48).

Amendment (VIII) to the Criminal Law of the People's Republic of China was issued by the Supreme People's Court in 2011, specifying the regulation for criminal organ trafficking. Interim Provisions on Human Organ Procurement and Allocation were implemented by the National Health and Family Planning Commission in 2013. The policy of donation-after-cardiac-death (DCD) was initiated in 2010 and Law of the People's Republic of China on the Red Cross Society was issued in 2017. Based on the above two laws, China has issued more than 30 regulatory documents to further enhance the supervision on the process of organ donation and transplantation, especially on prohibiting transplant tourism and regulating living donor organ transplantation (49).

The approval process of living donor organ donation and transplantation is strictly supervised by provincial and national-level health authorities. The Established National Organ Donation and Transplantation Committee is the top authority, with branches of organ donation, organ procurement and distribution, the medical system for organ transplantation, organ registration after transplantation and organ transplantation supervision. The China Organ Transplant Response System (COTRS) is the mandatory official organ allocation system, which performs automated patient-oriented organ match based on aboveboard scientific organ allocation polices. China Organ Donation Administrative Center and organ donation coordinators, China Organ Transplant Response System (COTRS), and Organ Procurement Organization (OPO) are the key components of this system (Figure 6).

The fairness, efficiency and safety of organ distribution are among the first priorities of the allocation. Chinese organ donors per million population (PMP) reached up to 4.53 in 2018 (Figure 7A). The Wuxi center has been authorized to 


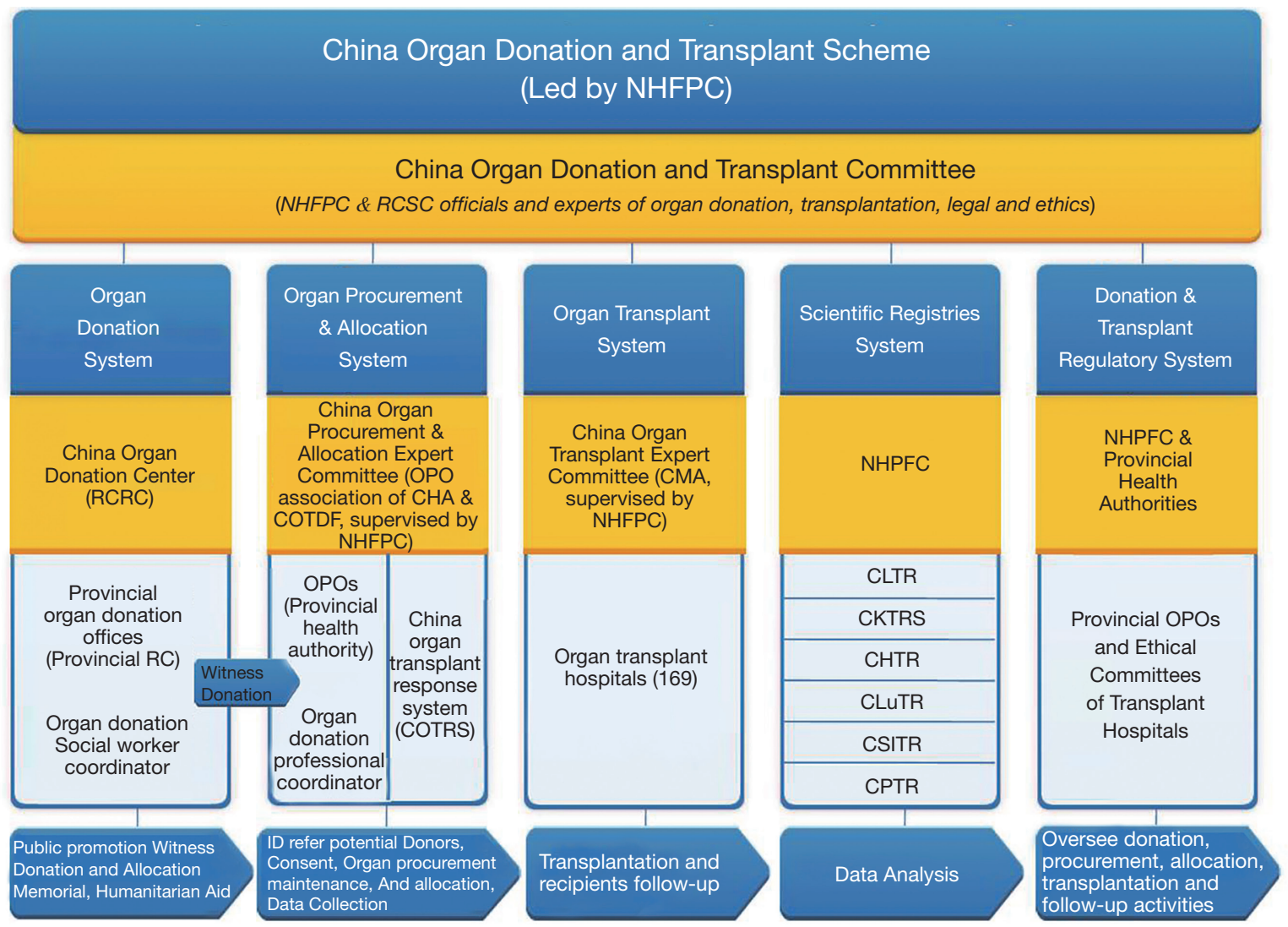

Figure 6 China organ donation and transplantation system structure, supervised by the National Health and Family Planning Commission (now nominated as the National Health Commission) with the steering committee board, composing of five systems (Reorganized from NHC official files).

take over the supervisor role of China lung transplant data in 2010. Detailed tracking information of donors and recipients have been required to be included in the system (Figure $7 B$ ). The Data Quality Control system has a tertiary structure demonstrated by transplant centers, national data centers, as well as national administrative departments (Figure 7C).

January $1^{\text {st }}, 2015$, has been widely recognized as the date when China officially announced that voluntary donated organs were to be the sole legal source of transplantable organs. This had a profound effect on academic society and public awareness on transplantation medicine. More than a million registered organ donors by the year 2019 have been announced, according to the China Organ Donation Administrative Center. Under the frame work of developing the "Guangdong-Hong Kong-Macao Greater Bay Area", tentative cooperation on the organ transplantation registry, allocation and sharing has raised great hope for patients in the Cross-Strait Four Regions since 2019.

\section{"Green Channel" for long-distance organ transportation}

To guarantee a solid pathway for transportation of the "gift of life", the National Health and Family Planning Commission, the Ministry of Public Security, the Ministry of Transport, Civil Aviation Administration of China, China Railway Corporation and the Red Cross Society of China jointly worked on the "green channel" construction (Figure 8). From May 6 ${ }^{\text {th }}$, 2016, the Codes of Organ Transportation were enacted with steering a 24-hour oncall liaison for dispatch. Once the destination hospital is confirmed, all-route transportation with the donated organ is authorized to have the first-priority-ambulance shuttling on clear roads in busy cities, without delay of going through highway toll stations, and with priority for flight/high-speed train security check and boarding. During rush-hour or busy times in the airport or train station, the flight or ride with the organs will take precedence of departure. As China has a vast territory with unevenly distributed medical and 
A

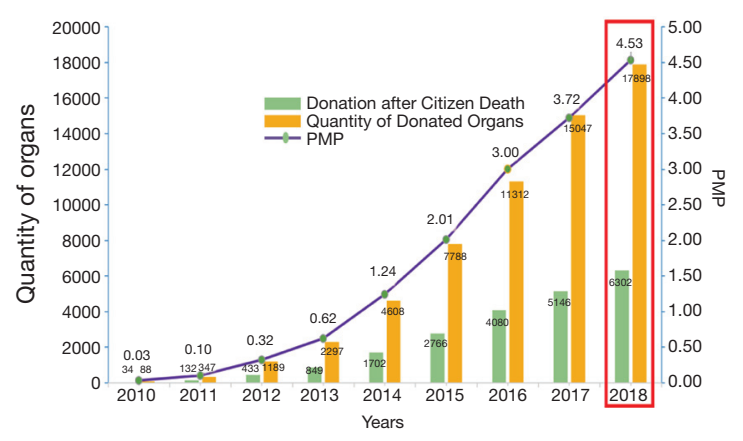

B

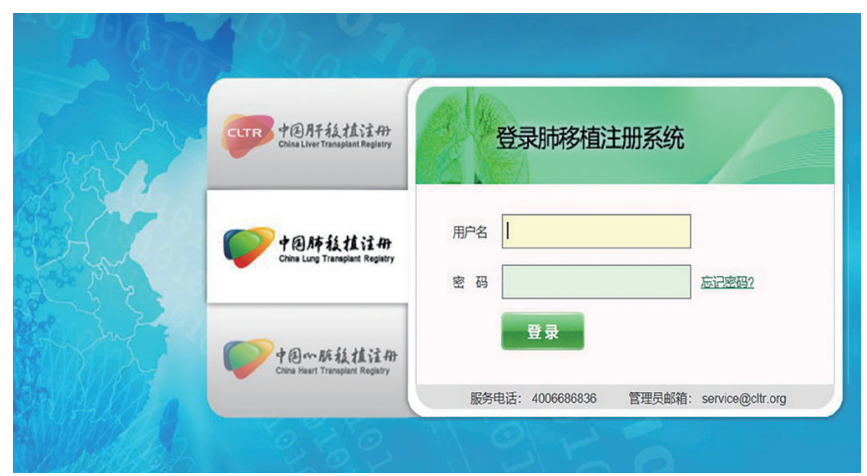

C

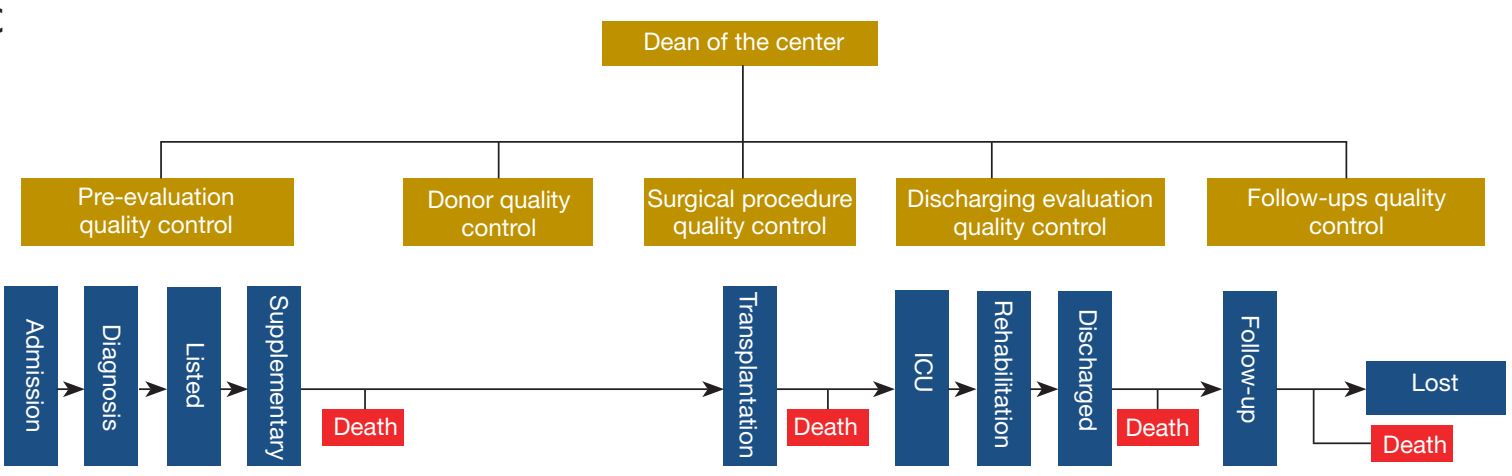

Figure 7 China lung transplantation registration. (A) Statistic data of yearly organ donation quantity and donors, presented by PMP (Data from National Health Commission). Registration system (B), quality management and control workflow (C) of lung transplantation data in China.
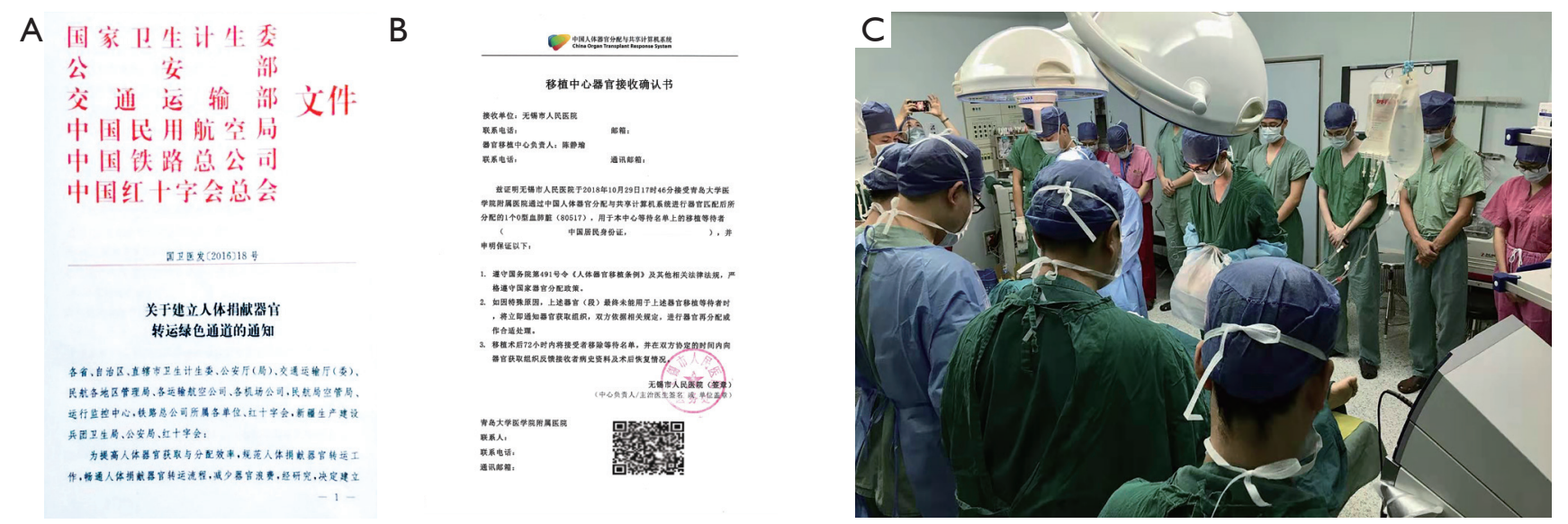

Figure 8 Organ donation, allocation and transplantation across China. (A) Official approval file for construction of the "Green channel" organ transplantation; (B) confirmation file for receiving the allocated organs; (C) before the donation procedure, surgeons stood in silent tribute for the donor. 
donor organ sources, organ procurement and maintenance teams have to respond to the demands with swift and precise arranged timing for travel and work on organs. This is a different model from the practice of transplant teams in western centers. However, with more centers having established the lung transplantation program, new emerging routes of organ transportation will be able to shorten the ischemic time, ensuring a high quality of organ maintenance.

\section{Public media as a sharing and educational tool to promote broadcasting}

To promote the development of lung transplantation, not only will surgical treatment techniques determine the survival and life quality, but public awareness and acceptance of this treatment will also be crucial for long-term growth. Currently in China, "WeChat" and "Weibo" Blog have been the main social media for mass media propaganda, exchanging and sharing of information among friends and acquaintances. The transplant teams have established their own webpages with articles to explain lung transplantation and organ donation, share information and introduce their centers. Patient groups (PGs) have also been established, with support from government or specific foundations for diseases, such as those for pulmonary artery hypertension, LAM, and pneumoconiosis. In these PGs, patients (postlung transplantation, or on the waiting list, or on evaluation, with their families), treating doctors, researchers (from institutions or the industry), and even lawyers or journalists work together to boost their knowledge while drawing more attention from people, both domestically and abroad. They are trying to tell their real stories in the "first person" way and proactively attend the biomedical research of the diseases they have been enduring (Figure 9).

\section{Coping with bottlenecks and future perspective}

Having overcome the learning curve for the surgical techniques, lung transplantation doctors may confront much more challenges than those in other organ transplantation in the peri-transplantation period. Particularly with the practices in China, bottlenecks constrain the further expansion of service with difficulties in covering a large area with high demand and an uneven distribution of qualified centers. For obtaining and preserving suitable donor lungs, a candidate donor lung from the donor on mechanical ventilation for days or even weeks and the need to spend days to receive consent from brain-death donors' family have always been especially challenging situations. Many donated lungs have been found to be colonized with microbes and culture positive upon evaluation. The vulnerable lungs were even required to travel thousands kilometers to where the recipients were located. Improper donated lung maintenance with pulmonary edema and multidrug-resistance bacterial infection interfered with the effective usage of grafts. A uniform standard of work-flow and comprehensible training are the key factors to maintain the quality of organ procurement.

Many recipients are reluctant to be evaluated or worrying about unbearable cost without reimbursement. Many elderly patients, who have good family support from many children, can afford the cost and match the criteria, are willing to be listed and transplanted. However, in younger patients, if they lack support, they may be hesitant at first and decide to do the transplant late in time. These candidates in the waiting list are always depending on ventilator or mechanical circulation support with more comorbidities.

With the aim to communicate and share experiences with centers from countries in Asia and abroad, so as to promote a healthier program development, the China Lung Transplantation Alliance (CLTA) with steering committee was announced to be established on September $21^{\text {st }}, 2018$ (Figure 10A). This is the first recognized collaborative organization in the China Mainland and was initiated by the chief of China Human Organ Donation and Transplantation, Professor Huang Jiefu with Academician Chen Wang and Dr. Jingyu Chen. They represented the stakeholders who contributed to lung transplantation development in China. Transplant teams in the Alliance work in cooperation on multi-lung procurement projects with concordant work-flow and transported allocated lungs within the shortest ischemic time and routes. Even if the procurement team's hospitals do not have recipients waiting for organs, they can help with other CLTA hospitals' teams for organ maintenance and transportation to save time from transportation (Figure 10B).

In Dr. Hardy's era, the development of lung transplantation techniques were closely related to translational research. Forerunners in China had also setup animal model experiments and pathophysiological research from the early days. In China, the development in the following areas is urgently needed and of strategic importance for further research in lung transplantation medicine. It is not uncommon that lung transplantation doctors to be excited about ex vivo lung perfusion's (EVLP) 


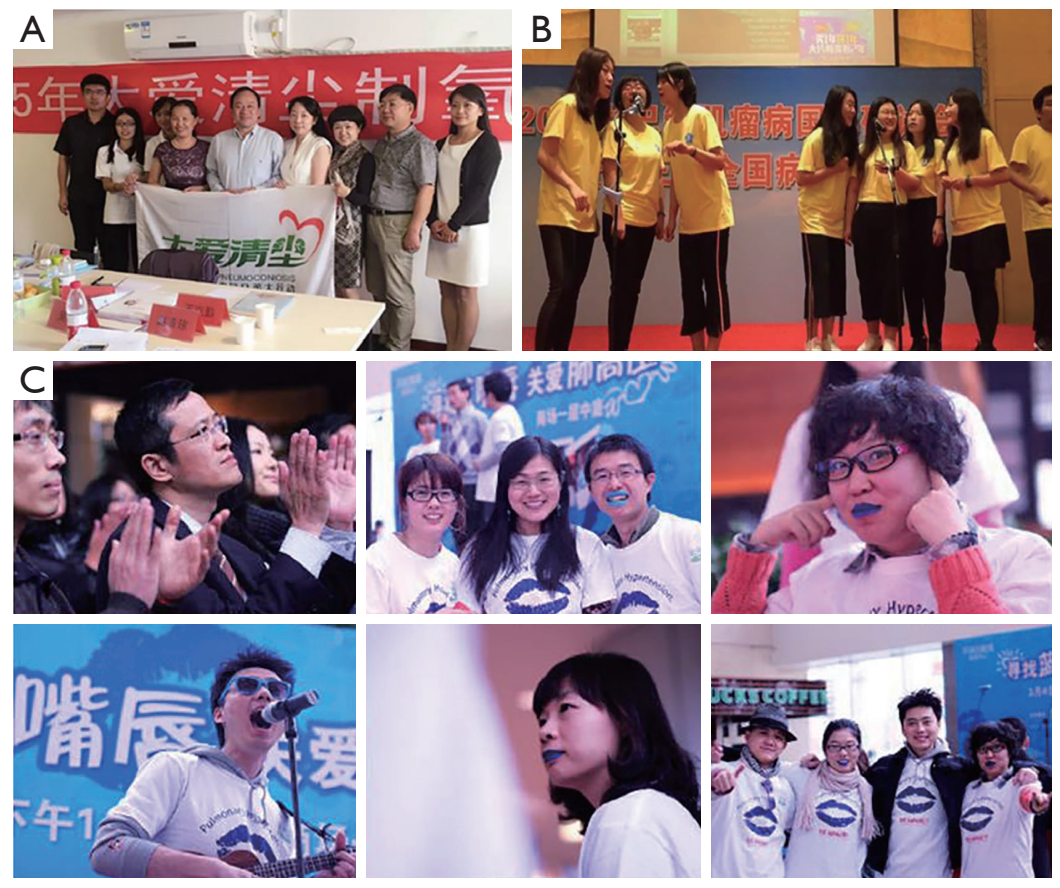

Figure 9 Patient Groups established for assisting better treatment for pneumoconiosis (A), to find suitable oxygen machine for patients (from "Love save pneumoconiosis" foundation and by courtesy of Dr. Jingyu Chen). (B) Patients education activities and research attendance of LAM patients (from "LAM CHINA" foundation, courtesy of Dr. Ji Zhang). (C) Commemoration of PAH day in 2012 by PAH patients and doctors, which was reported and promoted by PAH UK (from "iseek" foundation and by courtesy of Dr. Jingyu Chen).

A

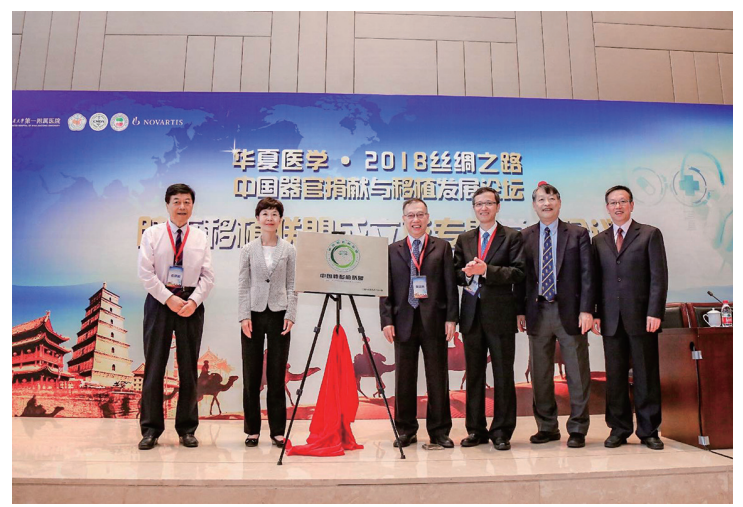

B

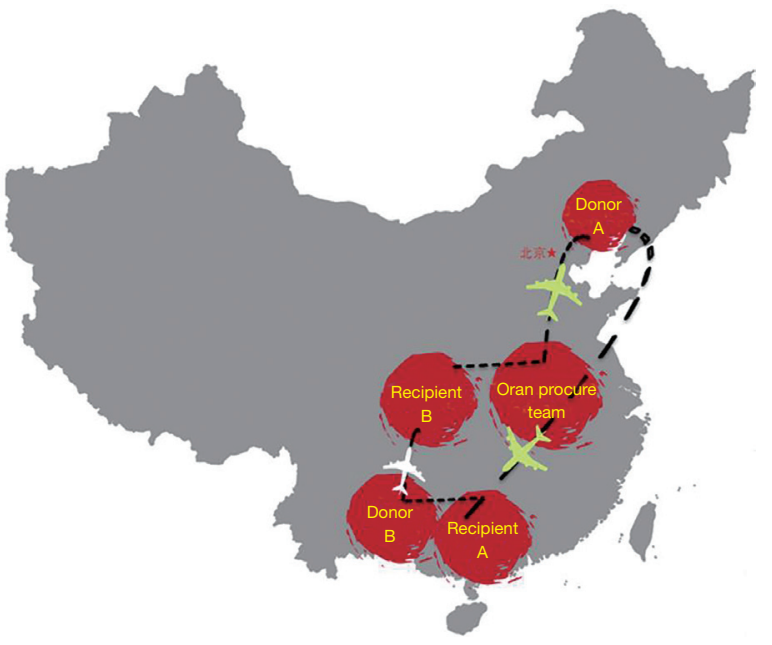

Figure 10 China Lung Transplantation Alliance (CLTA) and its operation illustration. (A) Establishing memorial ceremony of the China Lung Transplantation Alliance (CLTA), on Sep 21st, 2018 (courtesy of Dr. Jingyu Chen). (B) Representative model for alliance member operation. When receiving notification of simultaneously donation of two lungs, a "third" center of organ procurement team in the nearest location to both donors and recipients responds. A day of "to-and-fro" trip help three centers for donation and transplantation. [Map cited from http://bzdt.ch.mnr.gov.cn/ and approved number GS (2016) 1596]. 
innovative concept and design for use (50). High-impact papers and even larger registries have been on site (51). EVLP has been demonstrated to expand the range of graft tolerance during transportation and waiting time. Yet, the technique has been highly centralized in several specialized commercial entities. Considering the cost-benefit from the actual status of Chinese patients, a featured practical and translational research-oriented model might need to be explored to balance the financial and medical benefit. More biomarkers for early diagnosis of acute and chronic rejection as well as precise detection of infection using next generation of sequencing are also indispensable parts of our future research. In the next decade, $5 \mathrm{G}$ networks have the potential to provide more strength in the integration of remote evaluation and communication, and all-route organ transportation instant monitoring (52).

\section{Conclusions}

In China, with the largest population in East Asia, considerable accumulated data and experience with respect to cooperation in lung transplantation, have contributed to remarkable progress in recent years. History is not only for memorizing, but for understanding the future $(53,54)$. Change and progress in lung transplantation in China, also reflect the path of development for a "Healthy China" with distinct Chinese characteristics and a bright future.

\section{Acknowledgments}

We would like to express appreciation with respect to all the contributors involved in lung transplantation development in China as mentioned in the manuscript.

\section{Footnote}

Conflicts of Interest: The authors have no conflicts of interest to declare.

Ethical Statement: The authors are accountable for all aspects of the work in ensuring that questions related to the accuracy or integrity of any part of the work are appropriately investigated and resolved.

\section{References}

1. Demikhov VP. Transplantation of the heart, lungs and other organs. Eksp Khir Anesteziol 1969;14:3-8.
2. Langer RM. Vladimir P. Demikhov, a pioneer of organ transplantation. Transplant Proc 2011;43:1221-2.

3. Xin YL, Cai LP, Hu QB, et al. Human lung transplantation: a case report. Chin J Surg 1979;17:328-32.

4. Xin YL, Cai LP, Zhao ZW, et al. The second case report of human lung transplantation. Chin J Organ Transplant 1981;2:4-6.

5. Ou SL, Wan S. Lung transplantation in China. Book chapter. Cardiothoracic Surgery in China: Past, Present and Future. Chinese University Press; 1 edition (July 10, 2007).

6. Chen YP, Zhang ZT, Hang L, et al. Lung transplantation for pulmonary fibrosis: a case report. Chin J Surg 1996;34:25.

7. Zhao FR, Jiang YG, Ge B, et al. Lung transplantation: 1 case. Chin J Thorac Cardiovasc Surg 1998;14:237-8.

8. Zhao F, Jiang Y, Li N. Experience and lessons of lung transplantation. Zhonghua wai ke za zhi 1997;35:616-9.

9. Chen YP, Zhou QW, Hu YS, et al. Double-lung transplantation for the treatment of primary pulmonary hypertension. Chin J Thorac Cardiovasc Surg 1998;14:321-3.

10. Chen JY, Zheng MF, He, YJ, et al. Single lung transplantation in end-stage emphysema. Chin J Surg 2003;(6):7-9.

11. Toronto Lung Transplant Group. Unilateral lung transplantation for pulmonary fibrosis. $\mathrm{N}$ Engl J Med 1986;314:1140-5.

12. Hardy JD. Re-implantation and Homotransplantation of the Lung: Laboratory Studies and Clinical Potential. Ann Surg 1963:157:707-18.

13. Hardy JD. The first lung transplant in man (1963) and the first heart transplant in man (1964). Transplant Proc 1999;31:25-9.

14. Kantrowitz A. America's first human heart transplantation: the concept, the planning, and the furor. ASAIO J 1998;44:244-52.

15. Veith FJ, Blumenstock DA. Current research review. Lung transplantation. J Surg Res 1971;11:33-55.

16. Cooper JD, Pearson FG, Patterson GA, et al. Technique of successful lung transplantation in humans. J Thorac Cardiovasc Surg 1987;93:173-81.

17. Goldberg M, Lima O, Morgan E, et al. A comparison between cyclosporin $\mathrm{A}$ and methylprednisolone plus azathioprine on bronchial healing following canine lung autotransplantation. J Thorac Cardiovasc Surg 1983;85:821-6.

18. Mal H, Andreassian B, Pamela F, et al. Unilateral lung 
transplantation in end-stage pulmonary emphysema. Am Rev Respir Dis 1989;140:797-802.

19. Ota K. Current status of organ transplants in Asian countries. Transplant Proc 2004;36:2535-8.

20. Takagi H. Organ transplants still too few in Japan and Asian countries. Transplant Proc 1997;29:1580-3.

21. Date H, Aoe M, Nagahiro I, et al. Living-donor lobar lung transplantation for various lung diseases. J Thorac Cardiovasc Surg 2003;126:476-81.

22. Date H. Living-related lung transplantation. J Thorac Dis 2017;9:3362-71.

23. Ota K. Asian transplant registry. Transplant Proc 2001;33:1989-92.

24. Takagi H. Cadaveric \& living organ donation. Asian experience. Ann Transplant 2004;9:74-7.

25. Wei D, Gao F, Chen JY, et al. First successful double lung transplantation from brain death donor in China. Transplantation 2011;92:e12-3.

26. Hsin MKY, Wong CF, Yan SW, et al. The history of lung transplantation in Hong Kong. J Thorac Dis 2018;10:S1899-904.

27. Yang SM, Huang SC, Kuo SW, et al. Twenty-years of lung transplantation in Taiwan: Effects of cumulative institutional experience on early outcomes. J Formos Med Assoc 2017;116:862-8.

28. Sato M, Okada Y, Oto T, et al. Registry of the Japanese Society of Lung and Heart-Lung Transplantation: official Japanese lung transplantation report, 2014. Gen Thorac Cardiovasc Surg 2014;62:594-601.

29. Okumura M. Trends and current status of general thoracic surgery in Japan revealed by review of nationwide databases. J Thorac Dis 2016;8:S589-95.

30. Lee JG, Kim SY, Kim YT, et al. First Report of the Korean Lung Transplantation Registry. Transplant Proc 2018;50:2759-63.

31. Mao W, Chen J, Zheng $M$, et al. Initial experience of lung transplantation at a single center in China. Transplant Proc 2013;45:349-55.

32. Wang Y, Chen J, Wei D, et al. Bilateral lung transplant for bronchiectasis in asymmetric thorax: a case report. Exp Clin Transplant 2011;9:429-31.

33. Mao W, Xia W, Chen J, et al. Successful lung autotransplantation for central non-small-cell lung cancer: report of a case. Surg Today 2013;43:562-5.

34. Wang Y, Wei D, Wang Z, et al. Bilateral lung transplant for bronchioloalveolar carcinoma: first case in China. Exp Clin Transplant 2012;10:519-21.

35. Mao W, Xia W, Chen J. Lung transplantation for lung cancer. Ann Thorac Surg 2013;96:1910.

36. Mao W, Xia W, Chen J. Is lobar lung transplantation sufficient for patients with pokey thorax cavity? Eur J Cardiothorac Surg 2014;46:756.

37. Mao W, Xia W, Chen J. Distinct phenotypes of primary graft dysfunction after lung transplantation. Chest 2014;145:192-3.

38. Mao W, Xia W, Chen J. Concerns raised by lung sizemismatched transplantation. Chest 2012;142:542-3.

39. Zhang F, Xu H, Jiang S, et al. Value of preoperative pulmonary artery diastolic pressure on predicting primary graft dysfunction after bilateral lung transplantation for patients with idiopathic pulmonary fibrosis. Zhonghua Wei Zhong Bing Ji Jiu Yi Xue 2017;29:442-7.

40. Zhu S, Zhou M, Wei D, et al. Risk Analysis of Perioperative Death in Lung Transplant Patients With Severe Idiopathic Pulmonary Hypertension. Transplant Proc 2019;51:875-9.

41. Wei D, Gao F, Wu B, et al. Single versus bilateral lung transplantation for idiopathic pulmonary fibrosis. Clin Respir J 2019;13:376-83.

42. Gao F, Chen J, Wei D, et al. Lung transplantation for bronchiolitis obliterans syndrome after allogenic hematopoietic stem cell transplantation. Front Med 2018;12:224-8.

43. Xia W, Xu H, Mao W, et al. Extracorporeal membrane oxygenation as a bridge to lung transplantation. Zhonghua Wei Zhong Bing Ji Jiu Yi Xue 2018;30:1167-72.

44. Huang H, Feng R, Li S, et al. A CARE-compliant case report: Lung transplantation for a Chinese young man with idiopathic pleuroparenchymal fibroelastosis. Medicine (Baltimore) 2017;96:e6900.

45. Liu DR, Guo YQ, Li FT, et al. Allogenic single lung transplantation, 3 cases. Chin J Surg 2006;44:1581-2.

46. Liu DR, Guo YQ, Zhao FR, et al. Allogenic single lung transplantation, 7 cases. Chin J Tissue Eng Res 2008;12:10567-70.

47. Huang L, Chen W, Guo L, et al. Scopulariopsis/ Microascus Isolation in Lung Transplant Recipients: A Report of Three Cases and a Review of the Literature. Mycoses 2019;62:883-92.

48. Mao W, Xia W, Chen J. Regulation of lung transplantation in China. J Heart Lung Transplant 2012;31:1147-8.

49. Huang J. The "Chinese Mode" of organ donation and transplantation. Hepatobiliary Surg Nutr 2017;6:212-4.

50. Pan X, Yang J, Fu S, et al. Application of ex vivo lung perfusion (EVLP) in lung transplantation. J Thorac Dis 
2018;10:4637-42.

51. Jiao G. Evolving Trend of EVLP: Advancements and Emerging Pathways. SN Compr Clin Med 2019;1:287-303.

52. Anwar S, Prasad R. Framework for Future Telemedicine Planning and Infrastructure using 5G Technology.

Wireless Pers Commun 2018;100:193-208.

Cite this article as: $\mathrm{Wu} \mathrm{B}, \mathrm{Hu} C$, Chen $\mathrm{W}, \mathrm{He} \mathrm{J}$, Jiang G, Zhang J, Liu D, Li X, Wei D, Jiao G, Wang C, Chen J. China lung transplantation developing: past, present and future. Ann Transl Med 2020;8(3):41. doi: 10.21037/atm.2019.10.26
53. Festle M.J. Sociomedical History of Lung Transplantation, 1963-2000. In: Second Wind. PALGRAVE Studies in Oral History. Palgrave Macmillan, New York: Springer, 2012.

54. Kirklin JK, Mehra M, West LJ. Series, Monograph Volume 4, History of International Heart and Lung Transplantation. Elsevier, 2010. 